\title{
Instituições e crescimento econômico: os modelos teóricos de Thorstein Veblen e Douglass North
}

\author{
HERTON CASTIGLIONI LOPES*
}

Institutions and economic growth: The theoretical models of Thorstein Veblen and Douglass North. The aim of this work is to analyse the role of institutions in the economical growing. It searches for propose two theoretical models that explain the development, one is according to Thorstein Veblen and the other one is based on Douglass North. Thus, it summarises and compares the effects of the institutions growing and at the same time emphasizes the deviations and approximation on both theoretical chain. Beside the differences still exist, there is a research agenda that is approaching. In both theoretical models there are important concepts to analyse the effects of the institutions in the development.

Keywords: institutions; growth; Douglass North; Thorstein Veblen.

JEL Classification: B25; B52; O10; O43.

\section{INTRODUÇÃO}

Atualmente a teoria institucionalista reúne um corpo teórico muito vasto e abrangente. Existe uma série de vertentes teóricas, que têm feito grandes avanços no sentido de explicar a importância do campo de estudo institucionalista. ${ }^{1}$ Apesar dos seus recentes progressos, e por ser uma área de pesquisa em desenvolvimento,

\footnotetext{
"Doutor em Economia pela Universidade Federal do Rio Grande do Sul (UFRGS), professor adjunto da Universidade Federal da Fronteira Sul (UFFS).E-mail: herton.lopes@uffs.edu.br. O texto resulta, em parte, da minha tese de doutorado desenvolvida na UFRGS sob a orientação do prof. Octávio Augusto Camargo Conceição. Agradeço ao professor por despertar meu interesse no campo de estudo institucionalista e pelas orientações e discussões que balizaram o desenvolvimento deste trabalho.

${ }^{1} \mathrm{O}$ texto de Conceição (2002) apresenta as diversas abordagens institucionalistas, destacando uma síntese das correntes dos antigos institucionalistas, neoinstitucionalistas, novos institucionalistas, regulacionistas e evolucionários.
} 
ainda existe forte discussão sobre o papel das instituições no desenvolvimento econômico. Mesmo assim, o fato é que a teoria institucionalista tem crescido de importância, seja para explicar o funcionamento da economia ou para observar como a mudança institucional afeta o modo de vida das pessoas e a organização da produção nas diferentes nações.

Os precursores no estudo da área são autores da corrente teórica denominada "antigo" institucionalismo e se referem, principalmente, aos trabalhos desenvolvidos por Thorstein Veblen, John R. Commons e Wesley C. Mitchell, tendo no primeiro autor grande expressão atual. Apesar da sua importância teórica, o antigo institucionalismo acabou esquecido no período entre guerras, quando os EUA emergiam como grande potência mundial (Hodgson, 2007a). Seu declínio teórico abre espaço, a partir dos anos 1960, para outros estudiosos que procuraram incorporar as instituições na teoria econômica. São os denominados novos institucionalistas que têm feito questão da utilização do termo "novo" exatamente para se diferenciar dos teóricos que criticaram veementemente a forma de pensar economia predominante na virada para o século passado. Entre os principais expoentes do novo institucionalismo estão Douglass North, Ronald Coase e Oliver Williamson. ${ }^{2}$

$\mathrm{O}$ antigo institucionalismo ${ }^{3}$ se desenvolveu a partir de uma forte crítica ao neoclassicismo, principalmente as suas análises reducionistas e estáticas, com enfoque no equilíbrio ao invés da mudança. Por seu turno, o novo institucionalismo, ao mesmo tempo em que critica a teoria tradicional, mantém-se preso ao seu núcleo teórico, preocupando-se com aspectos específicos que não invalidam a tradição ortodoxa, mas reconhecendo seus problemas e tentando incorporar elementos mais consistentes na explicação dos problemas econômicos. Em outras palavras, o novo institucionalismo reconhece as inconsistências da ortodoxia, mas tenta corrigi-las na medida em que seu corpo teórico avança.

O antigo institucionalismo é, portanto, uma corrente teórica que parte de uma crítica "por fora" da teoria tradicional, enquanto o novo institucionalismo trabalha a partir de uma crítica "por dentro", procurando incorporar elementos mais eficientes na explicação dos fenômenos econômicos. Contudo, à medida que aconte-

\footnotetext{
${ }^{2}$ Foi exatamente Oliver Williamson quem cunhou o termo Nova Economia Institucional (NEI) para diferenciá-la do institucionalismo original.

${ }^{3}$ O prefácio da Teoria da Classe Ociosa, de Veblen (1912), traz o pensamento de Jacob Oser, sintetizando o que seria a essência do pensamento institucionalista. Para eles, a economia deveria ser analisada como uma totalidade e não somente como a soma das partes. Dessa forma, se enfatizava a importância das instituições na atividade econômica. Sua concepção teórica inspirava-se em Darwin e nas teorias evolucionistas, destacando que o fundamental era captar o movimento e a evolução das instituições econômicas ao invés de acreditar em uma tendência ao equilíbrio. Sua crença era na existência de mudanças cumulativas e desajustes na vida econômica. Longe de pensar em uma ordem harmônica que regula o funcionamento do mercado, acreditavam na existência de profundos choques de interesses na sociedade, cabendo ao Estado regular os conflitos com políticas que visassem ao bem comum e ao melhor funcionamento do sistema. Estavam também preocupados com a distribuição de renda, acreditando na necessidade de intervenção estatal para a adequada alocação de recursos e sua distribuição mais equinânime (Oser, 1983).
} 
cem os avanços teóricos dos diversos autores, observam-se claras convergências de pensamento e isto, em alguns casos, dificulta consideravelmente a delimitação entre o que se chama "novo" e o que se trata de "antigo" no estudo das instituições. Observando que as abordagens trazem contribuições consideráveis para compreender a relação entre instituições e desempenho, ${ }^{4}$ este trabalho propõe-se a uma importante contribuição teórica na medida em que procura apresentar uma análise do efeito das instituições no crescimento econômico a partir de Douglass North e Thorstein Veblen. Ao fazer isso, inevitavelmente o artigo explicita as divergências e aproximações conceituais nas duas teorias.

Demonstra-se ao longo do texto que, mesmo com as diferenças metodológicas, o pensamento de Douglass North tem sofrido grande avanço, enfocando a ideia de instituições para além de direitos de propriedade e regras formais. A aproximação com o institucionalismo de Veblen fica clara quando o autor incorpora em seus trabalhos a compreensão de que fatores como a aprendizagem, os modelos mentais, as crenças compartilhadas e sua evolução são fundamentais na explicação das instituições e da mudança institucional. Esses elementos exercem, assim, uma função muito semelhante aos hábitos mentais de Veblen no processo de emergência e evolução institucional.

Com vistas a atingir o proposto no trabalho, além desta introdução, o segundo item apresenta a teoria de Douglass North. Enfocam-se questões relativas à origem, à definição e à relação das instituições com o desempenho econômico. Em seguida incorporam-se elementos importantes para construção de um esquema de crescimento a partir da teoria do autor. $\mathrm{O}$ item terceiro traz a teoria institucionalista de Veblen e seus desenvolvimentos recentes. Nele são analisadas questões relativas ao conceito de instituições, a noção de evolução e mudança institucional, elementos fundamentais para entender-se o desenvolvimento. Em seguida, propõe-se uma sistematização da relação entre instituições e crescimento a partir de Thorstein Veblen e Douglass North, ao mesmo tempo em que se comparam alguns conceitos presentes nos dois autores (item quarto). Por fim, apresentam-se as considerações finais.

\section{DOUGLASS NORTH: INSTITUIÇÕES E DESEMPENHO}

Para compreender o pensamento de Douglass North sobre a relação entre instituições e desempenho parte-se de questões básicas desenvolvidas pelo autor para, em seguida, incorporar elementos que representam grande avanço na sua

\footnotetext{
${ }^{4}$ Dequech (2002) procurou demonstrar as dificuldades eminentes de delimitação entre o antigo e o novo institucionalismo. O autor começa sua análise criticando Hodgson (2000), que enfatiza a diferença entre o antigo e o novo institucionalismo a partir da noção de individualismo metodológico que toma os indivíduos como dados e livres de influências institucionais. Conclui que uma concepção atomística de indivíduos tende a ser insustentável para novos institucionalistas que reconhecem e enfatizam a função mais informativa das instituições, como é o caso de Douglass North.
} 
teoria institucionalista e sem os quais seria impossível propor um modelo que sistematize a mudança e o crescimento econômico.

\section{Instituições: origem, definição e sua relação com o desempenho econômico}

Os trabalhos institucionalistas de Douglass North iniciam por demonstrar as falhas da teoria neoclássica em tratar os determinantes do desempenho econômico ao longo da história. Embora sua análise parta dos conceitos tradicionais de desenvolvimento, em que a produção depende do estoque de capital (capital físico e humano), dos recursos naturais, da tecnologia ${ }^{5}$ e do conhecimento acumulado (North, 1984), sobressai sua crítica à teoria tradicional por não considerar os problemas na alocação de recursos que impedem o funcionamento dos mercados (North, 1994). Ou seja, para investir, aumentar o estoque de capital e viabilizar melhor desempenho econômico, a teoria não considera a existência de custos de informação e da incerteza, com os custos de transação daí decorrentes.

Para Douglass North a teoria neoclássica não foi e não tem sido eficiente em demonstrar as razões que levam às diferentes performances das economias ao longo do tempo (North, 1999). Ao discursar na entrega do Prêmio Nobel, North (1998) afirma categoricamente que esta incorre em dois erros fundamentais. Em primeiro lugar, não incorpora uma teoria das instituições e, em segundo, desconsidera a importância da história. A insatisfação do autor é com o fato de a teoria se preocupar exclusivamente com uma instituição: os mercados e as alterações que ocorrem nos preços relativos.

Então, Douglass North parte para o desenvolvimento de uma teoria das instituições e enfoca sua influência sobre o desempenho econômico. Ao invés de abordar unicamente os mercados, sua análise é mais complexa, priorizando as instituições, em suas diversas concepções, e enfocando os direitos de propriedade, que estimulam os investimentos produtivos, reduzem a incerteza futura, garantem os rendimentos dos inovadores e, assim, estimulam o aumento no estoque de capital físico e humano, o avanço do conhecimento, a produtividade e finalmente o desenvolvimento econômico (North, 1994). Constata que são as instituições, sejam elas políticas ou econômicas, que formam a estrutura de incentivos da sociedade. Portanto, o desempenho se torna uma decorrência das instituições e dos estímulos à inovação e a eficiência.

Além disso, ressalta a importância da análise histórica. A teoria tradicional não tem como prescrever políticas porque não incorpora a evolução das sociedades e, portanto, a evolução institucional e os incentivos aos investimentos produtivos. Para o autor, o tempo é importante porque permite analisar como acontece a mudança institucional, o avanço da humanidade e as trajetórias de desenvolvimento

\footnotetext{
${ }^{5}$ A tecnologia nesses termos joga um papel fundamental porque, ao ser tratada como endógena, é resultado da capacidade de inovação dos agentes, intimamente relacionada com o estoque de conhecimento em determinado período de tempo (North, 1984).
} 
que se estabelecem nas diferentes nações. Estudando-se a história é possível observar como os seres humanos agem sobre sua estrutura de incentivos (instituições) no sentido de viabilizar o atraso ou a prosperidade econômica.

Partindo da preocupação com o desempenho Douglass North define instituições de forma bastante objetiva e focada. Ao representarem a estrutura de incentivos elas são imposições formais (tais como leis, regras, constituições etc.) e informais (normas de comportamento, convenções, códigos de conduta etc.) da economia. Possuem uma importância fundamental porque, ao serem imposições criadas pelos seres humanos, acabam limitando suas interações ${ }^{6}$ (North, 1998, 1991).

Além de incentivos, as instituições são restrições que moldam as escolhas individuais, mas, ao mesmo tempo, são criação dos seres humanos que objetivam reduzir a incerteza em relação ao futuro e garantir um ambiente estável aos investimentos e a lucratividade do capital. Nas atividades diárias, os seres humanos se deparam com um conjunto de restrições que normalmente estão apresentadas na forma de leis ou de regras informais. Elas provêm de informações transmitidas socialmente, são parte da nossa cultura e interferem na forma como interpretamos o ambiente. Por isso, influenciam na conduta dos indivíduos e das organizações (North, 2003).

As instituições são fundamentais ao desempenho porque amenizam os problemas de utilização do mercado, agindo diretamente sobre os custos de transação. Os trabalhos de Douglass North nesse ponto retomam questões levantadas em Coase (1937) e Williamson (1999) ${ }^{7}$ ao demonstrar que no ato de produzir existem dois tipos de custos: os custos de transação e de produção. A teoria ortodoxa considera apenas os custos de produção porque as instituições recebem pouca importância em sua análise. Contudo, em mercados "reais", os custos de transação são significativos e o desempenho econômico vai ser determinado pela capacidade que as instituições possuem de amenizar a incerteza e reduzir os custos de utilização dos mercados. Por isso a importância da análise conjunta entre instituições (extrafirma) e tecnologia (intrafirma), pois essa interação determina os custos de produção e transação e, por consequência, os custos totais.

Metaforicamente falando, North (1998) afirma que as instituições e a forma como evoluem representam as regras do jogo e as empresas ou organizações são, portanto, os jogadores. Estas organizações podem ser políticas, econômicas, sociais

\footnotetext{
${ }^{6}$ A ideia de que as instituições limitam a ação dos indivíduos aproxima Douglass North de John R. Commons. Para este autor, instituição é uma ação coletiva que controla, libera e amplia a ação individual (Commons, 1931, p. 1)

${ }^{7}$ Pode-se dizer que este é um dos fatores que têm levado à classificação de North como pertencente ao Novo-Institucionalismo. Suas ideias convergem com trabalho clássico de Coase, em 1937, que explica a existência de empresas pelos custos na utilização do mercado e nas transações (Coase, 1937). Williamson (1999) parte de uma visão muito semelhante sobre a existência dos custos de transação, mas aborda com maior profundidade os aspectos internos de organização da firma. Trata-se de uma das suas grandes contribuições, pois, ao enfocar a racionalidade limitada e o oportunismo, a complexidade, a incerteza e a especificidade dos ativos, mostra como se altera a organização das empresas.
} 
e educativas. No contexto econômico tais organizações são tratadas normalmente como firmas, que se utilizam da matriz institucional (conjunto de regras formais e informais) para alcançar seus objetivos. Se essa matriz estimula os ganhos produtivos, as empresas e organizações serão promotoras do desenvolvimento. Do contrário, procurarão manter sua subsistência através de atividades pouco férteis.

Enfim, pode-se resumir a relação entre instituições e desempenho econômico a partir da seguinte visão. Devido à sua complexidade, o ambiente humano é permeado de incerteza. Como existe insegurança em relação ao futuro, devido às limitações cognitivas dos agentes ou mesmo a não ergodicidade ${ }^{8}$ do mundo, surgem os custos de transação. Então, os seres humanos desenvolvem instituições, compostas de restrições informais, em grande parte determinadas pela cultura da sociedade, e normas formais, que dizem respeito, entre outras, à definição dos direitos de propriedade que amenizam a incerteza dos investimentos produtivos. A matriz institucional, composta dessas restrições, vai determinar o surgimento das organizações, que podem ser econômicas, sociais e políticas. Estas organizações interagem entre si, com os recursos empregados e com a tecnologia, determinando os custos de produção. As firmas, ao trabalharem com os recursos, uma tecnologia específica e utilizarem o sistema de mercado, interagem com as instituições, definindo os custos de transação (Gala, 2003). Essa dinâmica define o desempenho econômico e a mudança institucional.

\section{Mudança institucional e crescimento econômico: elementos indispensáveis para a compreensão do desempenho}

Compreender a mudança institucional implica analisar a interação que se processa entre os agentes, representados por organizações (jogadores), e o marco institucional ou conjunto de instituições vigente. O papel dos agentes é fundamental no modelo de North, pois a complexidade ${ }^{9}$ da interação entre organizações no processo produtivo, no mercado ou na sociedade pode levar a uma necessidade de redefinição das regras do jogo (North, 1990, 1991, 1998). Essa posição fica clara quando afirma que "The continuous interaction between institutions and organizations in the economic setting of scarcity and hence competition is the key to institutional change" (North, 2003, p. 1). Ao focar nos agentes, seus estudos têm

\footnotetext{
${ }^{8}$ Para North (2005), um mundo não ergódico é aquele em que as mudanças são contínuas, o que impede a formação de expectativas estáveis em relação ao futuro, demandando enorme esforço cognitivo por parte dos agentes. Sua visão é semelhante à dos autores pós-keynesianos como a de Davidson (1994), que classifica as expectativas como sendo geradas por processos ergódicos e não ergódicos. Nesse último (mundo capitalista real), o processo de tomada de decisão se move ao longo do tempo e a incerteza não é mensurável.

${ }^{9}$ Em North (1991) fica claro que a complexidade dos mercados, na medida em que as relações de troca migram da pessoalidade para a impessoalidade, exige a criação de um aparato institucional (sistema de pesos, medidas, leis etc.) que garanta o comércio de longa distância.
} 
avançado para analisar como acontece o crescimento a partir dos indivíduos, da sua aprendizagem, das crenças e dos modelos mentais.

Para Douglass North, vivemos em um mundo não ergódico, um ambiente em que as mudanças são contínuas, inusitadas, atípicas, e os seres humanos precisam fazer um enorme esforço cognitivo para atingir a compreensão dos fenômenos econômicos e sociais (North, 2005). Em função disso, a premissa tradicional de racionalidade utilizada nos modelos econômicos mostra-se insuficiente para compreender as escolhas, como se processa a mudança e evolui o desempenho. Assim o enfoque recai sobre a forma como os indivíduos percebem a realidade, o que resulta do seu processo de aprendizagem e de seu modelo cognitivo, formado a partir de um contexto específico. Na opinião do autor, embora cada indivíduo tenha um processo próprio de aprendizagem e, portanto, um modelo cognitivo ímpar, as crenças e as percepções resultam de uma estrutura institucional e educacional comum e se disseminam sobre as sociedades e afetam seu crescimento.

A aprendizagem é responsável pela constante modificação dos modelos mentais, que são revisados, redefinidos ou rejeitados dependendo de sua habilidade em interpretar o ambiente (North et al., 2004; North, 2005). O processo de aprendizagem dá origem a modelos cognitivos individuais, responsáveis pela modelagem da realidade. Trata-se do desenvolvimento de uma estrutura por meio da qual se interpretam os sinais que recebem nossos sentidos. North $(1998,2005)$ observa que a estrutura inicial da aprendizagem é genética, mas seu desenvolvimento é resultado das experiências vivenciadas pelos agentes (essas experiências provêm do meio físico e do meio sociocultural). A partir da evolução dessas experiências os indivíduos formam os modelos mentais, que explicam e interpretam o meio no qual se inserem e, em última instância, determinam o comportamento social. Os modelos mentais não são estáticos, pois evoluem ao longo do tempo como resultado da vivência dos seres humanos. Quando são considerados adequados para interpretar os sinais emitidos pelo ambiente tornam-se relativamente estáveis e modelam um "sistema de crenças" (North et al., 2004). Se forem inconsistentes devem ser revistos para originar novas crenças.

Torna-se importante observar que a aprendizagem é relevante para explicar o funcionamento das economias na medida em que ela se torna um processo coletivo e determina o surgimento de modelos mentais compartilhados. O processo de aprendizagem pode acontecer no ambiente familiar e até mesmo dentro das diversas organizações sociais. No nível da sociedade, a evolução cultural é a responsável pelo crescimento e transmissão do conhecimento ao longo do tempo. Essa transmissão pode acontecer de uma forma teórica (pelo hábito de expressar ideias através de palavras), de forma prática (conhecimento prático / "knowing how") ou mesmo através da imitação de práticas de outros (cozinhar, andar de bicicleta, dirigir carro etc.). Então, é preciso trabalhar com o conhecimento incluindo todas as possíveis adaptações do passado ao presente e futuro (North et al., 2004).

Denzau e North (1994) já haviam descrito a importância dos modelos mentais compartilhados. Para eles, a cultura é o elemento para compartilhar as crenças entre os indivíduos, da mesma forma que garante a transferência intergeracional do co- 
nhecimento. Os modelos mentais compartilhados sustentam um sistema de crenças, que tem o papel fundamental de reduzir as divergências entre os indivíduos (North, 2005). As crenças são fundamentais para compreender a formação de instituições que, em seu conjunto, representam as estruturas sociais e econômicas. As instituições são, portanto, as representações externas que os modelos cognitivos individuais criam para interpretar o ambiente. São representações da consciência dos indivíduos, utilizadas para estruturar e organizar seu meio, mas com o papel fundamental de reduzir a incerteza (North, 1998). Enquanto as instituições se materializam na sociedade, os modelos mentais são as representações internas que os indivíduos criam para interpretar o ambiente. Assim, as ideologias ${ }^{10}$ dos indivíduos e as instituições sociais surgem como diferentes classes dos modelos mentais compartilhados, com o papel de gerar estabilidade em um ambiente complexo.

Enfim, o desempenho econômico, em Douglass North, está intimamente relacionado à compreensão do processo de aprendizagem, da formação dos modelos mentais compartilhados e das crenças que evoluem ao longo da história. São esses elementos que influenciam na formação das instituições e na mudança institucional. As crenças determinam a ação dos indivíduos no sentido de perpetuar uma estrutura institucional ou transformá-la, o que pode viabilizar, ou não, melhores condições de crescimento. Surge daí a concepção de path dependence, pois a evolução institucional que determina o desempenho econômico é resultado da cultura, da aprendizagem e dos modelos mentais, fatores que evoluem ao longo da história. Para entender esse processo se deve partir do nível cognitivo para o nível institucional que culminará, por fim, no nível econômico (North et al., 2004).

A política joga um papel fundamental nesse processo. Ao mencionar o caso de ascensão e queda da União Soviética, ${ }^{11}$ North (2005) descreve como elas podem alterar a percepção da realidade, as crenças e a estrutura institucional em determi-

\footnotetext{
${ }^{10}$ As ideologias são definidas por North e Denzau (1994) como uma estrutura compartilhada de modelos mentais que grupos de indivíduos possuem para fornecer uma interpretação do ambiente e uma prescrição de como ele deve ser estruturado. É a partir dos modelos mentais que surgem as ideologias. As pessoas não agem necessariamente de acordo com o que prega a racionalidade substantiva, mas sim influenciadas por seus mitos, dogmas, teorias etc. Em condições de incerteza, o que determina o comportamento dos indivíduos é sua aprendizagem, que ocorre a partir do compartilhamento de informações. Nesse caso, os agentes com origens culturais comuns apresentam uma aprendizagem semelhante que se reflete em teorias e modelos mentais análogos e com os quais interpretam o mundo. Por outro lado, agentes com formas de aprendizagem heterogêneas apresentam modelos mentais diferentes para interpretar as informações e tomar decisões.

${ }^{11}$ A ascensão da antiga União Soviética, significativamente influenciada pelos ideais de Marx e Lênin, mostrava as crenças de como o mundo deveria ser. Criou-se, então, uma matriz institucional que teve sucesso (caso da indústria) e falhas (caso da agricultura). As tentativas de corrigir as falhas condiziam com a crença da ortodoxia marxista. A matriz institucional sofreu contínuas modificações por estímulos externos (guerra) e internos (envolvendo os limites ideológicos do marxismo). O resultado foi, ao longo das décadas de 1950, 1960 e início de 1970, um rápido crescimento do produto, da tecnologia militar, do conhecimento científico e o advento de status de superpotência. O exemplo da União Soviética foi admirado por muitos países, mas logo a economia do país começou a declinar (1985). Tentaram-se reformas institucionais que resultaram ineficazes na solução do problema.
} 
nado período. É um processo contínuo que, ao ocorrer, causa significativas mudanças no ambiente humano, fazendo com que os modelos mentais, as crenças e instituições estejam em constante alteração. Exatamente por isso North (2005) afirma que o estudo do processo de mudança econômica deve começar por explorar os esforços dos indivíduos para lidar com a incerteza em um mundo complexo. Deve compreender o contínuo empenho dos seres humanos para tornar seu ambiente inteligível e reduzir as incertezas. Porém, esse grande esforço resulta em contínuas alterações no ambiente e, portanto, em novos desafios para o entendimento do mundo.

\section{O INSTITUCIONALISMO DE VEBLEN E OS CONCEITOS QUE PERMITEM ANALISAR O CRESCIMENTO}

$\mathrm{Na}$ teoria econômica, o campo de estudo institucionalista apresenta diversas concepções teóricas e, em função disso, uma amplitude significativa de definições. A visão de Veblen caracteriza instituições de uma forma sólida, que não está unicamente relacionada à ideia de regras ou organizações sociais. Por isso, sua definição é ampla, abrangente e consistente no campo de estudo institucionalista. Partindo da concepção teórica de Veblen, este item trabalha o conceito de instituições e a mudança institucional, incorporando elementos para a compreensão do crescimento.

\section{O conceito de instituições}

Para Veblen (1919), as instituições são definidas como hábitos estabelecidos pelo pensamento comum, de forma generalizada, pelos homens. São os hábitos de pensamento, ao tornarem-se coletivos, generalizados e enraizados no ambiente, que formam as instituições políticas, econômicas e sociais. Os hábitos são desenvolvidos quando os agentes procuram atingir determinados fins e estão relacionados a comportamentos repetidos, que reforçam a existência das instituições.

O hábito é uma tendência de comportamento, moldado pelas circunstâncias ambientais e transmitido culturalmente. Pode ser parcialmente inconsciente, mas afeta a consciência, a racionalidade e as ações dos indivíduos. Trata-se de repertórios submersos de comportamento potencial, pois eles podem ser desencadeados ou reforçados por um estímulo adequado ou devido ao contexto no qual o agente se insere (Dewey, 1922).

Para Veblen (1912), os hábitos mentais sofrem forte influência das exigências do sistema produtivo da sociedade. É a forma de produção vigente, mesmo ao lado das já superadas, que determina os hábitos mentais. Existe, dessa forma, um conjunto de hábitos que, direta ou indiretamente, é derivado do sistema produtivo. A partir da organização da produção e da sociedade, os agentes desenvolvem hábitos compartilhados, levando a ações que, ao serem socialmente aceitas, criam e reforçam as instituições. 
Hodgson (2006, 2007b) afirma que os hábitos compartilhados são a essência das instituições. Para ele, as instituições funcionam porque as regras são incorporadas aos hábitos predominantes de pensamento e de comportamento. ${ }^{12}$ Os hábitos são as matérias que constituem as instituições, proporcionando-lhes maior durabilidade, poder e autoridade normativa. Ao se reproduzir hábitos compartilhados de pensamento criam-se instituições fortes, mecanismos de conformismo e acordos de caráter normativo. A essência das instituições, sejam elas vistas como regras sociais estabelecidas informalmente, leis formais ou organizações, são, portanto, os hábitos mentais.

O hábito consiste no mecanismo psicológico que forma a base de muitos comportamentos seguidores de regras. Contudo, para que o hábito tenha uma característica de regra, tem de adquirir conteúdo normativo, ser potencialmente codificável. ${ }^{13}$ Além do mais, deve ser predominante no grupo, determinando incentivos e restrições para as ações individuais. Quando isso acontece, o comportamento dos agentes torna-se semelhante e os hábitos são desenvolvidos e reforçados entre a população. É nesse momento que a estrutura de regras ajuda a criar hábitos e preferências consistentes com a reprodução da própria estrutura social.

Enfim, na tradição de Veblen as instituições emergem a partir de hábitos comuns que surgem dos indivíduos e não podem confundir-se apenas com regras escritas ou instituições formais. Pelo contrário, as regras e as instituições formais de uma sociedade existem e são eficientes porque estão alicerçadas em hábitos compartilhados. Instituições que não estão de acordo com o pensamento e as formas de agir dos indivíduos estão fadadas a desaparecer ou funcionar de forma ineficiente porque destoam dos hábitos da população, formados a partir de um processo histórico.

\section{A evolução institucional em Veblen: incorporando conceitos para uma proposta de modelo de crescimento}

Assim como em Douglass North, a relação entre indivíduos e instituições é elemento presente na teoria institucionalista de Veblen. Hodgson (2002, 2007b) propõe uma interpretação em que tanto indivíduos como instituições sejam observados em conjunto, em um processo de evolução e reconstituição. Trata-se do conceito de reconstitutive downward causation, ${ }^{14}$ em que se demonstra que os

\footnotetext{
${ }^{12}$ Entre esses autores, Hodgson (2007b) menciona os trabalhos de Veblen (1899), Dewey (1922), Joas (1996), Twomey (1998) e Kilpinen (2000).

${ }^{13} \mathrm{O}$ termo "potencialmente codificável" demonstra que a desobediência às regras pode ser facilmente identificada no grupo. As regras seriam aceitas e seguidas pela maior parte dos indivíduos, mas quando um ou alguns deles não as seguem fica claro o caráter de desordem que, de alguma forma, é percebido ou julgado pelos demais agentes.

${ }^{14}$ Recentemente, em sua home page, Hodgson (2011, p. 1) utilizou o termo reconstitutive downward effect ao invés de reconstitutive downward causation. Segundo o autor, o sentido do termo é mantido, ainda que descrito de outra forma: "The meaning of what I previously described as 'reconstitutive
} 
agentes recebem influência institucional, mas ao mesmo tempo moldam as instituições a partir de hábitos compartilhados. O resultado é que as instituições exercem forte influência sobre os indivíduos (mais especificamente sobre o seu comportamento), mas os indivíduos são agentes ativos que podem alterar as instituições sociais. Em ambos os casos a relação pode ser reconstitutiva, em que tanto indivíduos como instituições podem ser profundamente modificados.

Nesse processo observa-se a ideia de evolução. Em Veblen a mudança e o crescimento não podem ser compreendidos sem uma análise da modificação dos hábitos mentais, assim como dos elementos que os afetam. Segundo Hodgson (2010) a evolução institucional deve ser vista a partir da interação entre instintos, hábitos, crenças e ação humana. Para o autor, os hábitos representam os meios a serem utilizados para a satisfação dos desejos instintivos e interagem no sentido de influenciar o comportamento porque estão muito relacionados ao processo de evolução biológica e social dos agentes.

Apesar da importância dos instintos, os hábitos tendem a assumir um papel mais importante nas decisões humanas porque afetam as crenças e o processo de deliberação, que não pode ser tratado como resultado da racionalidade individual. Nas palavras de Hodgson (2010, p. 7), ao comentar Veblen (1914), enquanto os instintos são "[...] essentially simple and directed to some concrete objective end Habits are the means by which the pursuit of these ends could be adapted in particular circumstances [...]".

Portanto, a deliberação e a ação dependem das crenças e dos hábitos, que são inerentes ao pensamento, à cultura e ao processo de evolução biológica (representado nos instintos). Nesse caso, mesmo as decisões racionais devem considerar o papel dos hábitos e das regras que estão presentes no momento da escolha. Os agentes tomam suas decisões seguindo regras e hábitos, mas as próprias regras somente existem porque são fundamentadas nos hábitos de pensamento (Hodgson, 2010).

Nessas relações está a ordem de desenvolvimento dos seres humanos, pois as crenças e a razão evoluem a partir dos instintos e das disposições habituais. Para Hodgson (2010), os elementos possuem uma hierarquia funcional, pois a razão

\footnotetext{
downward causation' is retained, but I shall henceforth describe it differently". Isso porque o termo 'causação' está mais relacionado à noção de explicação e determinação, deixando transparecer que as características dos agentes seriam determinadas pelas instituições ou pelas estruturas sociais ao invés de privilegiarem a interação entre ambos. Por isso, propõe utilizar o termo "efeito", que deixa maior espaço para o papel dos agentes individuais e suas interações, dando consistência às instituições ou estruturas presentes em um nível superior. Segundo Hodgson (2011), o termo reconstitutive downward effect acontece quando um sistema, que contém elementos de nível inferior, cria ou reafirma condições que podem ser relacionadas com as mudanças de natureza dos elementos desse nível. Para fins desse trabalho, continuaremos utilizando a denominação reconstitutive downward causation, pois as definições apresentadas demonstram que existe uma interação entre os agentes e as instituições, de forma que apenas a nomenclatura foi modificada para evitar equívocos (como, por exemplo, acreditar que as instituições determinam o comportamento e as crenças dos agentes, sem considerar suas características e interações).
} 
depende das crenças, estas dependem dos hábitos e os hábitos dependem dos instintos. Os hábitos e, por decorrência, as crenças e ações humanas, estão sujeitas a um processo de seleção e adaptação, resultando na evolução e mudança institucional. Além de um processo de seleção natural, que age no sentido de escolher os instintos mais importantes para a sobrevivência do organismo, na sociedade opera um processo de seleção cultural, que age sobre os hábitos mais propensos a sobreviver no ambiente social. É um processo importante para explicar a mudança e o mecanismo de decisão, pois a cultura cria e perpetua os hábitos mais adequados para determinadas épocas. ${ }^{15}$

De uma forma semelhante, a ação também passa por uma seleção e adaptação cultural, pois comportamentos repetidos e aceitos socialmente formam e reforçam os hábitos generalizados. Esses hábitos tornam a influenciar as crenças, ao mesmo tempo que são influenciados por elas, levando a deliberações e, novamente, a ação. Existe, nesse ponto, um mecanismo de autorreforço porque a ação vai, repetidamente, passar por um processo de seleção cultural reiterando os hábitos sociais que viabilizam a emergência das instituições. Exatamente por isso a capacidade de deliberação dos indivíduos depende da sua herança passada e das condições materiais da sociedade. No Darwinismo social, ao qual o pensamento de Veblen está filiado, a razão não aparece subitamente na evolução humana, mas depende dos nossos ancestrais e da aprendizagem que acontece ao longo da nossa história. Mesmo com alta capacidade de raciocinar ante os animais, a deliberação humana continua dependente dos instintos e das disposições habituais.

Enfim, a emergência e a consolidação das instituições acontecem a partir dos hábitos, pois quando eles enraízam-se na vida social, criam-se instituições fortes que são difíceis de ser modificadas. Exatamente por isso, Veblen (1912), em sua obra clássica A Teoria da Classe Ociosa, afirma que os homens procuram preservar os seus hábitos indefinidamente, exceto nos momentos em que as circunstâncias os obrigam a mudar. O teórico observa que a alteração dos hábitos estabelecidos é incômoda, já que envolve um grande esforço mental. Dessa forma, a mudança institucional deve ser vista a partir de uma análise evolucionária que ocorre em um contexto de seleção e adaptação. Muitos hábitos que não se adaptam a determinados contextos são eliminados, enquanto outros, ao serem aceitos no ambiente, se reforçam e permanecem enraizados na vida social. Portanto, para Veblen (1912), um processo de mudança institucional é cumulativo, se autorreforça, e, como unidade de seleção em um ambiente em evolução, está sujeito a mutação e seleção. Em sua concepção de instituições, o teórico norte-americano assume que a evolução se trata da mudança de hábitos mentais das várias classes da comunidade, em nível de cada indivíduo. A evolução e a mudança acabam por se tornar a evolução do homem e suas instituições.

\footnotetext{
${ }^{15}$ Esclarecimentos importantes sobre como operam os processos de seleção e adaptação no processo de mudança institucional são apresentados em Hodgson (1997).
} 


\section{AS INSTITUIÇÕES E O CRESCIMENTO: PROPONDO E COMPARANDO OS MODELOS A PARTIR DE VEBLEN E NORTH}

A partir dos conceitos apresentados anteriormente, o processo de crescimento, de acordo com a concepção de Douglass North, é esquematizado na Figura 1. Nela observa-se que o desempenho é decorrência das escolhas dos agentes em interação com o marco institucional vigente e em modificação ao longo do tempo. As escolhas e as instituições são resultado das crenças compartilhadas dos indivíduos, que surgem em função dos modelos mentais e evoluem pela aprendizagem. O esquema, além de explicar a evolução, demonstra como ocorre a deliberação e o processo de tomada de decisão, que vai além da tradicional teoria da escolha racional. Nesse esquema ainda é importante observar que os agentes podem ser representados pelas firmas que, com sua tecnologia de produção, interagem com as instituições, determinando o desempenho a partir dos custos de produção e transação. Trata-se de um esquema que, na própria ideia de Douglass North, fundamenta a compreensão do desempenho econômico das nações e também é amplamente dependente da evolução histórica das sociedades (ambiente evolutivo).

Figura 1: Esquema institucionalista de crescimento a partir de Douglass North

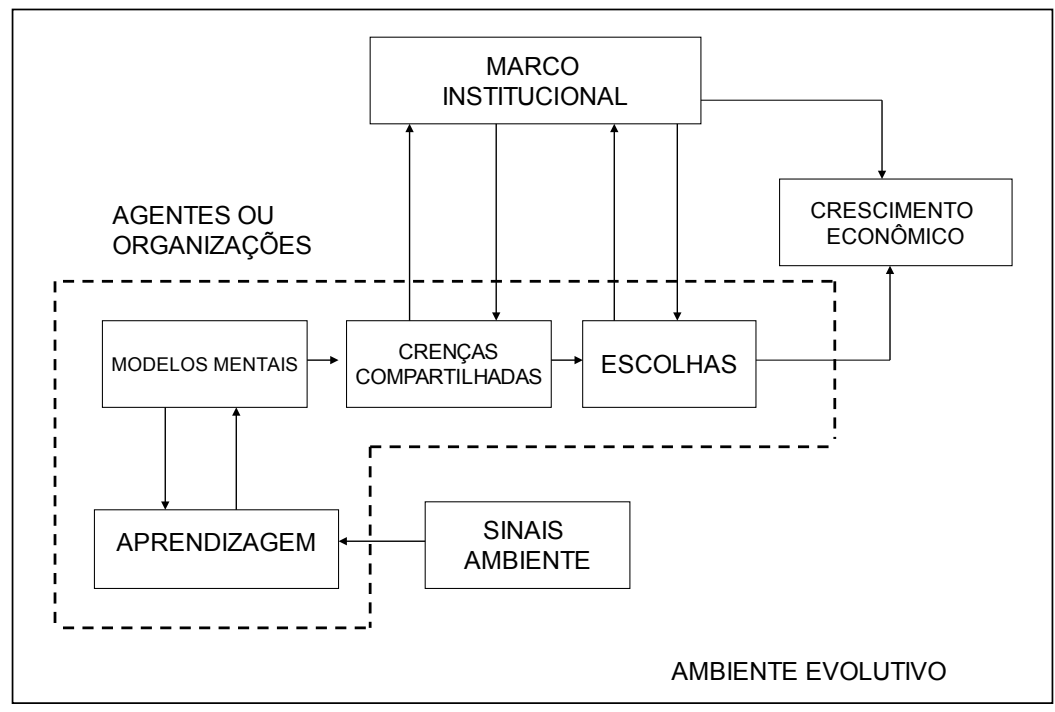

Fonte: Elaboração própria.

A Figura 2, por seu turno, propõe um esquema de crescimento a partir do institucionalismo de Veblen. Nela é retomado o conceito de reconstitutive downward causation, expresso na relação entre indivíduos, hábitos mentais e instituições. Da mesma forma, enfoca-se o papel das crenças, do processo de deliberação e ação, fatores amplamente dependentes do ambiente cultural, onde estão presentes os processos de seleção e adaptação. A ideia proposta é que, nesse modelo, o cres- 
cimento econômico aparece como dependente da ação dos agentes e das instituições, que ganham consistência a partir dos hábitos mentais. Estes afetam e são afetados pelas crenças e pela deliberação, levando a comportamentos que, junto com o marco institucional, são a chave para a compreensão da mudança e do crescimento econômico.

Embora nos escritos de Veblen não fique expressa a preocupação com o desempenho, é possível observar que as instituições afetam todo o funcionamento da sociedade, o que inclui as condições de produção. Tanto que o autor admite serem os próprios hábitos derivados do sistema produtivo e, quando enraizados na vida social, responsáveis por criar e reforçar a existência das instituições. Em função disso, a figura a seguir ousa registrar as instituições como determinantes das condições de produção. No caso das firmas, admite-se que suas ações e seu processo produtivo sofrem forte influência institucional, assim como se observa nos escritos de Douglass North.

Figura 2: Esquema institucionalista de crescimento a partir das ideias de Veblen

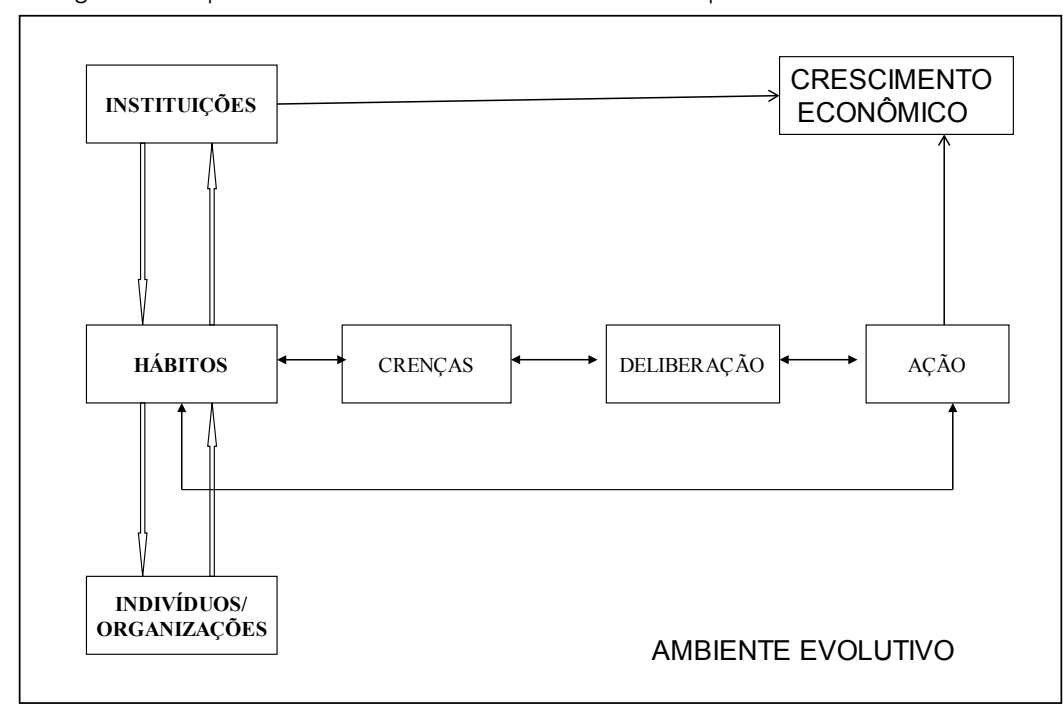

Fonte: Elaboração própria.

Conforme se constata, os dois modelos teóricos apresentam conceitos muito próximos. No caso do processo de deliberação, tanto North como Veblen expressam uma crítica à concepção de racionalidade e indivíduo presentes na teoria ortodoxa. Douglass North tem deixado claro que o pressuposto da racionalidade substantiva não se aplica quando se deseja analisar as decisões dos agentes em um ambiente complexo e, portanto, impregnado de incerteza em relação ao futuro. Reforça, então, a importância dos modelos mentais, das crenças e da aprendizagem no processo de decisão. Entender como os indivíduos aprendem ajuda a explicar a formação de uma estrutura cognitiva capaz de analisar os sinais emitidos pelo ambiente e captados pelo organismo humano. Esse processo molda as instituições 
que irão afetar o processo de produção, as transações no mercado e, assim, o crescimento.

A teoria de Veblen parte de uma crítica completamente diferenciada da concepção de indivíduo. ${ }^{16}$ Ao invés das falhas de racionalidade, procura trabalhar com a noção de hábitos de pensamento, que surgem sob influência dos instintos, mas estão muito relacionados aos comportamentos repetidos. O próprio raciocínio lógico e a forma como os agentes interpretam os fenômenos, ao mesmo tempo em que formam são formadores de hábitos, que se originam da nossa evolução biológica, social e cultural. Portanto, se reconhece que os hábitos agem sobre a racionalidade, mas desencadeando ações que podem ser inesperadas.

Por outro lado, a semelhança no pensamento dos autores se observa na comparação entre os hábitos de Veblen e os modelos mentais compartilhados de North, elemento que tem se apresentado de grande relevância na sua teoria. Observa-se que, embora partam de análises distintas, os hábitos e os modelos mentais são influenciados por fatores semelhantes. Em Veblen os hábitos surgem a partir das condições de produção vigentes em cada sociedade e são resultado de ações repetidas que condicionam a mente a pensar de determinada forma (Veblen, 1912). Daí tem-se a importância da história e do processo de evolução cultural, em que operam os processos de seleção e adaptação, conforme a teoria de Darwin. Já em North, os modelos mentais compartilhados são resultado do processo de aprendizagem, influenciados pela arquitetura genética, pelas experiências vividas no ambiente físico e sociocultural linguístico (a cultura). Aprendizagem nessa visão é “[...] the complex modification of the mental models according to the feedback received from de environment" (North et al., 2004, p. 76). Nesse contexto o desenvolvimento está presente tanto na concepção de evolução natural (genética) como na de evolução cultural.

Os autores ainda enfocam o papel das crenças compartilhadas tanto no processo de escolha e ação humana como na formação de instituições. No modelo proposto a partir de Veblen as crenças recebem forte influência dos hábitos mentais. Já em North os modelos mentais resultam da aprendizagem que geram crenças coletivas e estas, por sua vez, são responsáveis pela formação das instituições.

O que se pode afirmar categoricamente é que, enquanto nos trabalhos de Veblen os hábitos estão sujeitos a seleção e adaptação, em North é a aprendizagem que sofre um processo evolucionário. Para o autor: "[...] learning is an evolutionary process of trial and error, and failure to solve a problem leads to the trial of a new solution" (North et al., 2004, p. 76). Esse processo é relativamente flexível, levando a alteração nos modelos mentais como forma de solucionar os constantes problemas que provêm do ambiente.

Nas duas teorias cabe observar a influência que as instituições exercem sobre

\footnotetext{
${ }^{16}$ North (2005) reconhece a influência de ações não racionais (religião, mitos, dogmas etc.) no processo de decisão. No entanto, continua na busca por explicar a racionalidade das ações que levam os agentes a melhores condições produtivas.
} 
os indivíduos e, por consequência, sobre o crescimento econômico. Nos trabalhos de North as instituições são criação humana que tem o papel fundamental de restringir o comportamento individual. Elas emergem a partir das crenças compartilhadas e são essencialmente restrições, ou regras que dizem aos empreendedores como devem ou não agir; por isso sua importância quando se analisa o crescimento. Porém, em Douglass North os indivíduos também mudam suas preferências e agem no sentido de criar e modificar as instituições existentes. Esse fenômeno está presente nas ideias de Veblen que são retomadas em Hodgson $(2007 b, 2010)$ a partir do conceito de reconstitutive downward causation.

Douglass North define instituições como regras do jogo ou normas formais e informais. Já no institucionalismo de Veblen as instituições são essencialmente formas de pensar compartilhadas na sociedade. Retomando as ideias do autor, Hodgson (2007b) descreve instituições como um sistema de regras sociais estabelecidas e enraizadas para estruturar as relações sociais, sendo os hábitos o elemento fundamental para compreender como as regras se afirmam na sociedade. ${ }^{17}$ Assim, em Douglass North, para avançar na compreensão da performance econômica, é fundamental analisar a interação das instituições com os mercados. Já no institucionalismo de Veblen elas não estão unicamente voltadas para esse fim. Hodgson (2006) afirma que não podem ser vistas apenas como restrições, que impõem sanções aos agentes e se confundem com o marco legal da economia. Como Douglass North se mantém fortemente vinculado à teoria neoclássica, procura definir instituições como normas, especialmente formais, que delimitam as interações entre as organizações no sistema de mercado. Por outro lado, a concepção de Veblen enfoca muito mais a emergência institucional a partir dos indivíduos, embora se reconheça que as instituições também podem ser restrições. A diferença fundamental está, portando, na ênfase e no sentido de causalidade. Enquanto para North as instituições têm um papel muito mais importante no sentido de restringir as ações dos agentes e imputar-lhes punições caso se desviem do que está proposto, no institucionalismo de Veblen as instituições emergem dos indivíduos e as regras somente funcionam porque são incorporadas aos hábitos. Contudo, mesmo que a ênfase dos Novos Institucionalistas recaia sobre a necessidade de regramento do sistema de mercado, North incorpora conceitos que vão além de normas jurídicas e direitos de propriedade. Importante é observar que, mesmo com concepções diferenciadas de instituições, nas duas correntes teóricas se reconhece a importância do campo de estudo institucionalista para o desempenho.

\footnotetext{
${ }^{17}$ No mesmo trabalho, o autor procura fazer a distinção entre instituições, regras, convenções e organizações. Para o teórico, as instituições são um sistema de regras sociais estabelecidas determinadas pelos hábitos. As regras são entendidas como arranjos ou disposições transmitidas socialmente e potencialmente codificáveis, em que na circunstância X se deve fazer Y. Já as convenções são instâncias particulares das regras. E as organizações são instituições especiais que envolvem: 1) o critério para estabelecer suas fronteiras e distinguir os seus membros dos não membros; 2) princípios de poder em relação a quem está no comando; e 3) cadeias de comando, delineando responsabilidades para dentro da organização.
} 
Compreender o crescimento, portanto, implica a análise dos diversos conceitos expressos nas Figuras 1 e 2. Sistematizando o que foi apresentado, para Douglass North é a mudança no ambiente humano e a mudança institucional que podem levar ao melhor desempenho econômico. Essa mudança resulta da interação do marco institucional com as escolhas e crenças compartilhadas, destacando-se a importância dos modelos mentais e do processo de aprendizagem dos agentes, ou organizações, que atuam em um ambiente competitivo. Assim como a mudança em Douglass North se explica a partir da relação entre aprendizagem e o processo adaptativo dos modelos mentais, a dependência da trajetória é explicada de forma muito semelhante. Não é apenas a estrutura institucional, expressa em normas formais, que determina a inércia, mas sim a própria estagnação dos modelos mentais. Se eles são demasiadamente rígidos para se adaptar a novas circunstâncias tem-se um forte elemento que impede a mudança social e econômica (path dependence). Em Veblen, a explicação da mudança institucional deve partir da interação entre indivíduos e instituições, mas em uma concepção metodologicamente diferente da expressa em North. Naquele autor, a mudança institucional acontece a partir de um processo de seleção natural e cultural. A ação dos agentes, fator fundamental para compreender a evolução, resulta do processo de deliberação e este é significativamente influenciado pelas crenças. As crenças, por sua vez, têm origem nos hábitos de pensamento, formados a partir da cultura, mas sofrendo influência dos instintos. As ações, ao afetarem as crenças e os hábitos, são fundamentais para a mudança, que acontece a partir da alteração dos hábitos mentais. Ainda convém lembrar que na concepção de Veblen as ações dos agentes sofrem forte influência do processo de imitação. Ou seja, os indivíduos procuram incorporar comportamentos aceitos na coletividade. Surpreendentemente esse fato também é reconhecido no processo de aprendizagem descrito em North. Para o autor o conhecimento pode ser transmitido de forma teórica e prática, sendo a imitação a forma de transmissão do conhecimento prático (North et al., 2004).

\section{CONSIDERAÇÕES FINAIS}

O objetivo do trabalho foi analisar o papel das instituições no crescimento econômico a partir da proposta de dois modelos teóricos, um de acordo com o pensamento de Douglass North e outro a partir do institucionalismo de Thorstein Veblen. Ao enfocar essa questão, inevitavelmente explicitou-se a convergência teórica nos trabalhos dos dois autores, bem como algumas diferenças persistentes.

No modelo teórico proposto a partir do institucionalismo de Douglass North observou-se que o crescimento resulta da interação entre o marco institucional vigente e as escolhas dos indivíduos ou das firmas no seu processo de produção. Porém, elementos fortemente afetados pelas crenças, modelos mentais e processo de aprendizagem que acontece ao longo do tempo. Assim, observa-se que quanto mais Douglass North avança no sentido de explicar a mudança institucional, mais se aproxima dos conceitos desenvolvidos por Veblen. Isso porque na teoria de 
Veblen o crescimento pode ser interpretado a partir da interação entre as ações dos indivíduos e as instituições que são sustentadas por hábitos coletivos e crenças da sociedade.

Portanto, os teóricos têm sofrido uma considerável aproximação conceitual. As diferenças continuam porque o institucionalismo de North mantém-se excessivamente preocupado em explicar o desempenho a partir das falhas da teoria neoclássica. Por isso sobressai sua definição de instituições como normas e indivíduos que procuram agir racionalmente na melhor aplicação de recursos. Ao contrário de North, a teoria institucionalista de Veblen está menos preocupada com os resultados, mas se torna fundamental para explicá-lo. Nessa visão, as instituições não têm, necessariamente, o objetivo de melhorar o desempenho econômico, mas são essenciais na sua compreensão.

Por fim, ainda existem muitas questões a serem analisadas nos dois autores. Descobrir como opera a mente dos agentes, a formação de hábitos, o processo de aprendizagem e as crenças ainda são elementos que carecem de pesquisa na área institucionalista. Extrapolar o campo de estudo da economia em direção a outras ciências, tais como biologia, sociologia e psicologia, é o caminho para responder a essas questões, compreender a relação entre indivíduos e instituições e desvendar os mistérios no desenvolvimento das sociedades. Nesse ponto, o campo de estudo institucionalista, apesar de inacabado, tem feito significativos avanços.

\section{REFERÊNCIAS BIBLIOGRÁFICAS}

COASE, R. (1937 [1993]). The nature of the firm: origins, evolution, and development. New York/ Oxford: Oxford University.

COMMONS, J.R. (1931). “Institutional economics”. American Economic Review. v. 21, pp.648-657

CONCEIÇÃO. O.A.C. (2002). "A contribuição das abordagens institucionalistas para a constituição de uma teoria econômica das instituições”. Ensaios FEE, Porto Alegre, v. 23, n. 1, p. 77-106.

CONCEIÇÃO. O.A.C (2007). "Além da transação: Uma comparação do pensamento dos institucionalistas com os evolucionários e pós-Keynesianos”. Revista Anpec. Disponível em <http://www. anpec.org.br/revista/vol8/vol8n3p621_642.pdf. Acesso 20/de março de 2012>.

DAVIDSON, P. (1994). Post Keynesian Macroeconomic Theory. Aldershot, Edward Elgar.

DENZAU, A.; NORTH, D. (1994). "Shared mental models: ideologies and institutions". Kylos, 47 (1): 3-31. Disponível em <http://129.3.20.41/eps/eh/papers/9309/9309003.pdf>. Acesso 19 de dezembro de 2011.

DEQUECH, D. (2002). "The demarcation between the "old" and the "new" institutional economics: Recent complications". Journal of Economic Issues. Vol. 36. No. 2. p. 565-72.

DEWEY, J. (1922). Human Nature and Conduct: An Introduction to Social Psychology. New York: Henry Holt and Company.

GALA, P. (2003). “A teoria institucional de Douglass North” Revista de Economia Política. v. 23, n. 2 (90), p. 89-105.

HODGSON, G.M. (2002). "The hidden persuaders: institutions and individuals in economic theory." Cambridge Journal of Economics, Oxford, v. 27, n. 2, p. 159-75.

HODGSON, G.M. (2011). Downward causation - some second thoughts. Watford (UK). Disponível em: <http://www.geoffrey-hodgson.info/downward-causation.htm>. Acesso em: 26 ago. 2011.

HODGSON, G.M. (1997). Economia e evolução: o regresso da vida à teoria econômica. Oeiras: Celta. 
HODGSON, G.M. (2006). "What are institutions?” Journal of Economic Issues. Vol. XL No. 1. p. $1-25$.

HODGSON, G.M. (2000). "What is the essence of institutional economics?" Journal of Economic Issues. 34 , no. 2. p. 399-412

HODGSON, G.M. (2007a). "The revival of veblenian institutional economics”. Journal of Economic Issues, Armonk (USA), v. XLI, n. 2, p. 325-340.

HODGSON, G.M. (2010). "Choice, habit and evolution”, Journal of Evolutionary Economics. 20(1), pp. 1-18.

HODGSON, G.M. (1993). "Institucional economics: surveying the "old" and the "new"." Metroeconomica, Oxford [s. 1.], v. 44, n. 1, p. 1-28.

HODGSON, G.M. (2007b). "Institutions and individuals: interaction and evolution”. Organization Studies, Thousand Oaks (USA), v. 28, n. 1, p. 95-116.

NORTH, D.C.; MANTZAVINOS, C.; SHARIQ, S. (2004) "Learning, institutions, and economic performance. Perspectives on politics. Vol. 2. No 1. P. 1-19.

NORTH, D.C. (1994). Custos de Transação, Instituições e Desempenho Econômico. Rio de Janeiro: Instituto Liberal. p. 1-25.

NORTH, D.C. (1998). Desempeño Económico en el Transcurso de los Años. Estocolmo. Disponível em: <www.eumed.net.cursecon/textos/north-nobel.htm>. Acesso em: 17 fev. 2009.

NORTH, D.C. (2003). Five Propositions about institutional change. Disponível em http://129.3.20.41/ eps/eh/papers/9309/9309001.pdf. Acesso 26 de jun de 2012.

NORTH, D.C. (1999). Institutional Change: a framework of analyses. Disponível em http://ecsocman. hse.ru/data/853/760/1216/9412001.pdf. Acesso 28 de junho de 2012.

NORTH, D.C. (1990). Institutions, institutional change and economic performance. Cambridge: Cambridge University Press.

NORTH, D.C. (1991). “Institutions”. Journal of Economic Perspectives, Pittsburgh (USA), v. 5, n. 1, p. 97-112.

NORTH, D.C. (1984). Structure and Change in Economic History. New York: W.W. Norton and Co.

NORTH, D.C. (2005). Understanding the process of economic change. Princeton/Oxford: Princeton University Press.

OSER, J. Prefácio da classe ociosa. In: VEBLEN, T. B (1983). A Teoria da Classe Ociosa: Um Estudo Econômico das Instituições. São Paulo: Abril Cultural.

VEBLEN, T. (1912[1983]). A Teoria da Classe Ociosa: Um Estudo Econômico das Instituições. São Paulo: Abril Cultural.

VEBLEN, T. (1914). The Instinct of Workmanship, and the State of the Industrial Arts. New York: Macmillan.

VEBLEN, T. (1919). The Place of Science in Modern Civilization and Other Essays. New York: Huebsch. WILLIAMSON, O.E. (1999). The Economics and Transaction Costs. New York: Free Press. 